\title{
Thermochemical and Theoretical Studies of 2-Hydroxyquinoxaline, 2,3-Dihydroxyquinoxaline, and 2-Hydroxy-3-methylquinoxaline
}

\author{
M. A. V. Ribeiro da Silva,* M. A. R. Matos, C. M. A. Rio, and M. S. Miranda \\ Centro de Investigação em Química, Departamento de Química, Faculdade de Ciências da Universidade do \\ Porto, Rua do Campo Alegre, 687, P-4169-007 Porto, Portugal
}

\author{
V. M. F. Morais \\ Instituto de Ciências Biomédicas Abel Salazar, Universidade do Porto, P-4099-003 Porto, Portugal
}

Received: February 22, 2000; In Final Form: April 24, 2000

\begin{abstract}
The standard $\left(p^{\circ}=0.1 \mathrm{MPa}\right)$ molar enthalpies of formation for crystalline 2-hydroxyquinoxaline, 2,3-dihydroxyquinoxaline, and 2-hydroxy-3-methylquinoxaline were derived from the standard molar enthalpies of combustion, in oxygen, at $T=298.15 \mathrm{~K}$, measured by static bomb combustion calorimetry. The standard molar enthalpies of sublimation, at $T=298.15 \mathrm{~K}$, of the three compounds were measured by Calvet microcalorimetry. The derived standard molar enthalpies of formation in the gaseous phase are $45.9 \pm 4.3$ $\mathrm{kJ} \cdot \mathrm{mol}^{-1}$ for 2-hydroxyquinoxaline, $-(179.2 \pm 5.3) \mathrm{kJ} \cdot \mathrm{mol}^{-1}$ for 2,3 -dihydroxyquinoxaline, and $-(8.8 \pm$ 4.9) $\mathrm{kJ} \cdot \mathrm{mol}^{-1}$ for 2-hydroxy-3-methylquinoxaline. In addition, theoretical calculations using the density functional theory and the B3LYP/6-311G** hybrid exchange-correlation energy functional were performed for these molecules in order to obtain the most stable geometries and to access their relative stability. The theoretical results are in general good agreement with experimental findings.
\end{abstract}

\section{Introduction}

In previous work we have studied benzodiazines ${ }^{1}$ and some methyl pyrazines as well as 2,3-dimethylquinoxaline. ${ }^{2}$ In the present work, we continue with the study of substituted quinoxalines to extend the thermochemical data basis for these kinds of compounds for a better understanding of the effect of substituents on the energetics of nitrogen heterocycles. We report the standard molar enthalpies of formation of 2-hydroxyquinoxaline (2-OHQ), 2,3-dihydroxyquinoxaline (2,3-DOHQ), and 2-hydroxy-3-methylquinoxaline (2-OH-3-MeQ) in the gaseous state obtained from measurements of combustion energies using a static bomb calorimeter and from the values of the respective enthalpies of sublimation measured by Calvet microcalorimetry. Although the hydroxyquinoxalines likely exist in the keto-form in the solid phase, as shown in the crystal structure of 2-hydroxyquinoxaline, ${ }^{3}$ these compounds may likely exist in the hydroxy-form (enol-form) in the gaseous phase. The geometries of these molecules were obtained using the density functional theory and the B3LYP hybrid exchange-correlation energy functional. Single-point B3LYP/6-311G** energy calculations allowed us to study the height of the $\mathrm{O}-\mathrm{H}$ torsional barrier, the relative stability, and the $\mathrm{O}-\mathrm{H}$ bond dissociation energy of the three hydroxyquinoxalines.

\section{Experimental Section}

Materials. The compounds were obtained from Aldrich Chemical Co. The 2-hydroxyquinoxaline was recrystallized several times from ethanol. The 2,3-dihydroxyquinoxaline and 2-hydroxy-3-methylquinoxaline were purified by repeated vacuum sublimation. The purification process was repeated until the

* To whom correspondence should be addressed. E-mail: risilva@ fc.up.pt. combustion results were consistent and the carbon dioxide recovery ratios were satisfactory. The average ratios, together with the standard deviation of the mean, of the mass of carbon dioxide recovered to that calculated from the mass of sample were $0.9996 \pm 0.0004$ for 2-hydroxyquinoxaline, $0.9999 \pm$ 0.0009 for 2,3-dihydroxyquinoxaline, and $1.0007 \pm 0.00022$ for 2-hydroxy-3-methylquinoxaline. Purity was also confirmed by elemental microanalysis and DSC.

Combustion Calorimetry. The combustion experiments were performed with a static bomb calorimeter; the apparatus and technique have been described., ${ }^{4,5}$ The energy equivalent of the calorimeter was determined from the combustion of benzoic acid (Bureau of Analyzed Samples, Thermochemical Standard, BCS-CRM-190 p), having a massic energy of combustion, under standard bomb conditions, of $-(26431.8 \pm 3.7) \mathrm{J} \cdot \mathrm{g}^{-1}$. The calibration results were corrected to give the energy equivalent, $\epsilon$ (calor), corresponding to the average mass of water added to the calorimeter: $3119.6 \mathrm{~g}$. From nine calibration experiments, $\epsilon$ (calor) $=(15911.2 \pm 1.5) \mathrm{J} \cdot \mathrm{K}^{-1}$, where the uncertainty quoted is the standard deviation of the mean. This value was used for the study of 2-hydroxyquinoxaline and 2,3-dihydroxyquinoxaline. For 2-hydroxy-3-methylquinoxaline, the same calorimeter with a different bomb was used, and the value of $\epsilon$ (calor) $=$ $(16013.8 \pm 1.2) \mathrm{J} \cdot \mathrm{K}^{-1}$ was obtained from six calibration experiments. Combustion experiments were made in oxygen at 3.04 $\mathrm{MPa}$, with $1 \mathrm{~cm}^{3}$ of water added to the bomb. In all combustion experiments, $n$-hexadecane (Gold Label, Aldrich) was used to moderate and to make the combustions complete. Two samples of $n$-hexadecane were used. The massic energy of combustion of the sample of $n$-hexadecane used for 2-hydroxyquinoxaline and 2,3-dihydroxyquinoxaline was $\Delta_{\mathrm{c}} u^{\circ}=$ $-(47156.9 \pm 1.2) \mathrm{J} \cdot \mathrm{g}^{-1}$, and the massic energy of combustion of the sample of $n$-hexadecane used for 2-hydroxy-3-methyl- 
TABLE 1. Typical Combustion Experiments at $T=298.15$ K

\begin{tabular}{|c|c|c|c|}
\hline & 2-OHQ & 2,3-DOHQ & 2-OH-3-MeQ \\
\hline$m\left(\mathrm{CO}_{2}\right.$, total $) / \mathrm{g}$ & 1.62698 & 1.78532 & 1.99655 \\
\hline$m^{\prime}(\mathrm{cpd}) / \mathrm{g}$ & 0.31155 & 0.45526 & 0.52299 \\
\hline$m^{\prime \prime}$ (fuse) $/ \mathrm{g}$ & 0.00440 & 0.00388 & 0.00276 \\
\hline$m^{\prime \prime \prime}(n$-hexadecane $) / g$ & 0.27956 & 0.25421 & 0.22473 \\
\hline$\Delta T_{\mathrm{ad}} / \mathrm{K}$ & 1.35978 & 1.40693 & 1.59516 \\
\hline$\epsilon_{\mathrm{f}} /\left(\mathrm{J} \cdot \mathrm{K}^{-1}\right)$ & 16.50 & 16.49 & 16.54 \\
\hline$\Delta m\left(\mathrm{H}_{2} \mathrm{O}\right) / \mathrm{g}$ & 0.0 & 0.0 & -0.1 \\
\hline$-U(\mathrm{IBP}) / \mathrm{J}$ & 21658.17 & 22409.14 & 25570.29 \\
\hline$-\Delta U\left(\mathrm{HNO}_{3}\right) / \mathrm{J}$ & 25.79 & 37.13 & 47.10 \\
\hline$\Delta U(\mathrm{ign}) / \mathrm{J}$ & 1.19 & 1.19 & 1.15 \\
\hline$-\Delta U_{\Sigma} / \mathrm{J}$ & 10.25 & 12.76 & 14.06 \\
\hline$-\Delta U(\mathrm{carb}) / \mathrm{J}$ & 0.00 & 0.00 & 0.00 \\
\hline$-\Delta U(n$-hexadecane $) / \mathrm{J}$ & 13183.00 & 11987.98 & 10595.00 \\
\hline$-\Delta U($ fuse $) / \mathrm{J}$ & 71.46 & 63.01 & 44.82 \\
\hline$-\Delta_{\mathrm{c}} u^{\circ} /\left(\mathrm{J} \cdot \mathrm{g}^{-1}\right)$ & 26854.37 & 22639.96 & 28429.15 \\
\hline
\end{tabular}

quinoxaline was $\Delta_{\mathrm{c}} u^{\circ}=-(47145.8 \pm 1.3) \mathrm{J} \cdot \mathrm{g}^{-1}$. For all experiments, ignition was made at $(298.150 \pm 0.001) \mathrm{K}$. The electrical energy for ignition was determined from the change in potential difference across a capacitor when discharged through the platinum ignition wire. For the cotton-thread fuse, empirical formula $\mathrm{CH}_{1.686} \mathrm{O}_{0.843}$, the massic energy of combustion $\Delta_{\mathrm{c}} u^{\circ}=-16250 \mathrm{~J} \cdot \mathrm{g}^{-1} \cdot{ }^{6}$ Corrections for nitric acid formation were based on $-59.7 \mathrm{~kJ} \cdot \mathrm{mol}^{-1}$ for the molar energy of formation of $0.1 \mathrm{~mol} \cdot \mathrm{dm}^{-3} \mathrm{HNO}_{3}(\mathrm{aq})$ from $\mathrm{N}_{2}, \mathrm{O}_{2}$, and $\mathrm{H}_{2} \mathrm{O}(1) .{ }^{7}$ Corrections for carbon formation were based on the massic energy of combustion of carbon $\Delta_{\mathrm{c}} u^{\circ}=-33 \mathrm{~kJ} \cdot \mathrm{g}^{-1} .^{8}$ The amount of substance used in each experiment was determined from the total mass of carbon dioxide produced after allowance for that formed from the cotton-thread fuse and from the $n$-hexadecane, and that lost due to carbon formation. An estimated value of $1.13 \mathrm{~g} \cdot \mathrm{cm}^{-3}$ for the relative densities of 2-hydroxyquinoxaline, 2,3-dihydroxyquinoxaline, and 2-hydroxy-3-methylquinoxaline was assumed. An estimated pressure coefficient of specific energy $(\partial u / \partial p)_{T}=-0.2 \mathrm{~J} \cdot \mathrm{g}^{-1} \cdot \mathrm{MPa}^{-1}$ at $T=298.15 \mathrm{~K}$, a typical value for most organic compounds, was assumed. The massic energies of combustion, $\Delta_{\mathrm{c}} u^{\circ}$, for the compounds were calculated by the procedure given by Hubbard et al. ${ }^{8}$ The relative atomic masses used were those recommended by the IUPAC Commission. ${ }^{9}$

Sublimation Calorimetry. The standard enthalpies of sublimation of 2-hydroxyquinoxaline, 2,3-dihydroxyquinoxaline, and 2-hydroxy-3-methylquinoxaline were measured using the vacuum sublimation drop microcalorimetric method. ${ }^{10}$ Samples of about 2-5 $\mathrm{mg}$ of each compound contained in a thin glass capillary tube sealed at one end were dropped at room temperature into the hot reaction vessel, in a high-temperature Calvet microcalorimeter held at $T=492 \mathrm{~K}$ for 2-hydroxyquinoxaline, at $T=564 \mathrm{~K}$ for 2,3-dihydroxyquinoxaline, and at $T=437 \mathrm{~K}$ for 2-hydroxy-3-methylquinoxaline, and then removed from the hot zone by vacuum sublimation. The observed enthalpies of sublimation were corrected to $T=298.15$ $\mathrm{K}$, using $\Delta_{298.15 \mathrm{~K}}^{T} H_{\mathrm{m}}^{\circ} /\left(\mathrm{kJ} \cdot \mathrm{mol}^{-1}\right)=36.73,60.32$, and 28.76, respectively, for 2-hydroxyquinoxaline, 2,3-dihydroxyquinoxaline, and 2-hydroxy- 3-methylquinoxaline. These $\Delta_{298.15 \mathrm{~K}}^{T} H_{\mathrm{m}}^{\circ}$ values were estimated by a group method based on the values of Stull et al. ${ }^{11}$ The microcalorimeter was calibrated in situ for these measurements using the reported enthalpy of sublimation of naphthalene. ${ }^{11}$

\section{Experimental Results}

Results for a typical combustion experiment are given in Table 1, where $\Delta m\left(\mathrm{H}_{2} \mathrm{O}\right)$ is the deviation of the mass of water
TABLE 2. Values of the Massic Energy of Combustion, $\Delta_{\mathrm{c}} u^{0} / \mathrm{J} \cdot \mathrm{g}^{-1}$, at $T=298.15 \mathrm{~K}$

\begin{tabular}{ccc}
\hline 2 -OHQ & $2,3-\mathrm{DOHQ}$ & 2-OH-3-MeQ \\
\hline 26870.70 & 22652.71 & 28419.61 \\
26850.35 & 22639.96 & 28411.64 \\
26871.71 & 22655.76 & 28426.65 \\
26865.92 & 22631.20 & 28406.30 \\
26863.18 & 22631.12 & 28429.15 \\
26854.37 & 22651.14 & 28417.47 \\
26848.20 & 22635.58 & \\
& 22636.64 & \\
& $-<\Delta_{\mathrm{c}} u^{\circ}>/ \mathrm{J} \cdot \mathrm{g}^{-1}$ & \\
$26860.6 \pm 3.6$ & $22641.8 \pm 3.5$ & $28418.5 \pm 3.5$
\end{tabular}

added to the calorimeter from $3119.6 \mathrm{~g}$ and $\Delta U_{\Sigma}$ is the correction to the standard state. Samples were ignited at $T=298.15 \mathrm{~K}$, so that

$$
\begin{aligned}
& \Delta U(\mathrm{IBP})= \\
& \quad-\left\{\epsilon(\text { calor })+\Delta m\left(\mathrm{H}_{2} \mathrm{O}\right) c_{\mathrm{p}}\left(\mathrm{H}_{2} \mathrm{O}, \mathrm{l}\right)+\epsilon_{\mathrm{f}}\right\} \Delta T_{\mathrm{ad}}+\Delta U_{\mathrm{ign}}
\end{aligned}
$$

where $\Delta U(\mathrm{IBP})$ is the energy inherent to the isothermal bomb process, $\epsilon_{\mathrm{f}}$ is the energy associated with the contents of the bomb after combustion, $\Delta T_{\mathrm{ad}}$ is the adiabatic temperature rise, and $\Delta U_{\text {ign }}$ is the ignition energy. The remaining quantities in Table 1 are as previously defined. ${ }^{8}$

The individual results for the standard massic energies of combustion, $\Delta_{\mathrm{c}} u$, obtained in all the experiments together with the mean values and their standard deviations calculated for each compound are given in Table 2. Table 3 lists the derived standard molar energy and enthalpy of combustion, $\Delta_{\mathrm{c}} U_{\mathrm{m}}^{\circ}(\mathrm{cr})$ and $\Delta_{\mathrm{c}} H_{\mathrm{m}}^{\circ}(\mathrm{cr})$, and the standard molar enthalpy of formation for the compounds in the crystalline state at $T=298.15 \mathrm{~K}$, $\Delta_{\mathrm{f}} H_{\mathrm{m}}^{\circ}(\mathrm{cr})$. In accordance with normal thermochemical practice, the uncertainty assigned to the standard molar enthalpy of combustion is twice the overall standard deviation of the mean and includes the uncertainties in calibration and in the values of the auxiliary quantities used. ${ }^{12}$ To derive $\Delta_{\mathrm{f}} H_{\mathrm{m}}^{\circ}$ (cr) from $\Delta_{\mathrm{c}} H_{\mathrm{m}}^{\circ}(\mathrm{cr})$, the standard molar enthalpies of formation of $\mathrm{H}_{2} \mathrm{O}(\mathrm{l})$ and $\mathrm{CO}_{2}(\mathrm{~g})$, at $T=298.15 \mathrm{~K},-(285.830 \pm 0.042)$ $\mathrm{kJ} \cdot \mathrm{mol}^{-113}$ and $-(393.51 \pm 0.13) \mathrm{kJ} \cdot \mathrm{mol}^{-1},{ }^{13}$ were used. For each compound, at least six independent sublimation determinations were performed, yielding the average $\Delta_{\mathrm{cr}}^{\mathrm{g}} H_{\mathrm{m}}^{\circ}$ values also given in Table 3 , with uncertainties of twice the standard deviation of the mean. From the values for the standard molar enthalpies of formation, $\Delta_{\mathrm{f}} H_{\mathrm{m}}^{\circ}(\mathrm{cr})$, and of sublimation, $\Delta_{\mathrm{cr}}^{\mathrm{g}} H_{\mathrm{m}}^{\circ}$, of the crystalline compounds, the values of the standard molar enthalpies of formation in the gaseous state, $\Delta_{\mathrm{f}} H_{\mathrm{m}}^{\circ}(\mathrm{g})$, were derived (Table 3).

\section{Theoretical Calculations and Discussion}

The equilibrium geometries of all substituted quinoxalines have been obtained through full geometry optimization within the framework of density functional theory (DFT) using the B3LYP ${ }^{14}$ hybrid exchange-correlation energy functional to represent the exchange and correlation energy potentials together with the Pople 6-311G** triple- $\zeta$ valence plus polarization (tzvp) basis set. ${ }^{15}$

The resulting optimized geometries (see Figure 1 and Tables 4 and 5, respectively, for the bond lengths and bond angles) indicate that the substituted quinoxalines are planar molecules, with the $\mathrm{O}-\mathrm{H}$ substituent always being coplanar with the aromatic ring. This finding is in agreement with a similar behavior found for phenol and substituted phenols ${ }^{16,17}$ and is a clear indication that delocalization of electronic density into the 
TABLE 3. Derived Standard $\left(p^{\circ}=0.1 \mathrm{MPa}\right)$ Molar Values at $T=298.15 \mathrm{~K}$

\begin{tabular}{lcccrr}
\hline & $-\Delta_{\mathrm{c}} U_{\mathrm{m}}^{\circ}(\mathrm{cr}) / \mathrm{kJ} \cdot \mathrm{mol}^{-1}$ & $-\Delta_{\mathrm{c}} H_{\mathrm{m}}^{\circ}(\mathrm{cr}) / \mathrm{kJ} \cdot \mathrm{mol}^{-1}$ & $\Delta_{\mathrm{f}} H_{\mathrm{m}}^{\circ}(\mathrm{cr}) / \mathrm{kJ} \cdot \mathrm{mol}^{-1}$ & \multicolumn{1}{c}{$\Delta_{\mathrm{cr}^{\mathrm{g}}}{ }^{\circ} H_{\mathrm{m}}^{\circ} / \mathrm{kJ} \cdot \mathrm{mol}^{-1}$} & $\Delta_{\mathrm{f}} H_{\mathrm{m}}^{\circ}(\mathrm{g}) / \mathrm{kJ} \cdot \mathrm{mol}^{-1}$ \\
\hline 2-OHQ & $3925.7 \pm 1.3$ & $3925.7 \pm 1.3$ & $-79.9 \pm 1.7$ & $125.8 \pm 4.0$ & $45.9 \pm 4.3$ \\
2,3-DOHQ & $3671.3 \pm 1.4$ & $3670.1 \pm 1.4$ & $-335.5 \pm 1.7$ & $156.3 \pm 5.5$ & $-179.2 \pm 5.3$ \\
2-OH-3-MeQ & $4551.9 \pm 1.8$ & $4553.1 \pm 1.8$ & $-131.8 \pm 2.2$ & $123.0 \pm 4.4$ & $-8.8 \pm 4.9$
\end{tabular}

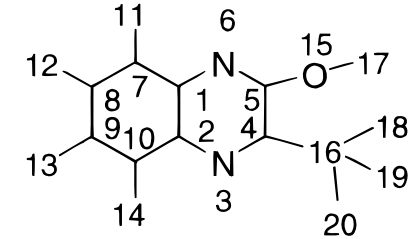

Figure 1. Atom numbering scheme for hydroxymethylquinoxaline.

TABLE 4. Calculated Bond Lengths of Substituted Quinoxalines $(\AA)$

\begin{tabular}{cccc}
\hline & $2-\mathrm{OHQ}$ & $2,3-\mathrm{DOHQ}$ & 2-OH-3-MeQ \\
\hline $1-2$ & 1.426 & 1.421 & 1.422 \\
$2-3$ & 1.369 & 1.373 & 1.368 \\
$3-4$ & 1.304 & 1.294 & 1.299 \\
$4-5$ & 1.432 & 1.447 & 1.443 \\
$5-6$ & 1.302 & 1.294 & 1.307 \\
$6-1$ & 1.368 & 1.374 & 1.369 \\
$1-7$ & 1.414 & 1.409 & 1.412 \\
$7-8$ & 1.378 & 1.379 & 1.377 \\
$8-9$ & 1.415 & 1.410 & 1.412 \\
$9-10$ & 1.377 & 1.379 & 1.378 \\
$10-2$ & 1.414 & 1.409 & 1.411 \\
$7-11$ & 1.084 & 1.083 & 1.083 \\
$8-12$ & 1.085 & 1.084 & 1.084 \\
$9-13$ & 1.085 & 1.084 & 1.084 \\
$10-14$ & 1.084 & 1.083 & 1.083 \\
$5-15$ & 1.347 & 1.344 & 1.350 \\
$4-16$ & 1.086 & 1.344 & 1.500 \\
$15-17$ & 0.968 & 0.969 & 0.968 \\
$16-18$ & & 0.969 & 1.089 \\
$16-19$ & & & 1.094 \\
$16-20$ & & & 1.094
\end{tabular}

TABLE 5. Calculated Bond Angles of Substituted Quinoxalines (deg)

\begin{tabular}{cccc}
\hline & 2-OHQ & 2,3-DOHQ & 2-OH-3-MeQ \\
\hline $1-2-3$ & 120.8 & 120.3 & 120.2 \\
$2-3-4$ & 117.4 & 117.9 & 116.9 \\
$3-4-5$ & 121.4 & 121.8 & 123.9 \\
$4-5-6$ & 123.1 & 121.8 & 119.6 \\
$5-6-1$ & 116.7 & 117.9 & 118.4 \\
$6-1-2$ & 120.6 & 120.3 & 120.9 \\
$2-1-7$ & 119.2 & 119.5 & 119.6 \\
$1-7-8$ & 119.9 & 120.0 & 120.0 \\
$7-8-9$ & 120.9 & 120.5 & 120.3 \\
$8-9-10$ & 120.2 & 120.5 & 120.8 \\
$9-10-2$ & 120.1 & 120.0 & 119.9 \\
$10-2-1$ & 119.7 & 119.5 & 119.4 \\
$1-7-11$ & 118.2 & 118.1 & 117.9 \\
$7-8-12$ & 119.7 & 119.9 & 120.1 \\
$8-9-13$ & 119.7 & 119.7 & 119.5 \\
$9-10-14$ & 122.2 & 121.9 & 121.9 \\
$4-5-15$ & 117.0 & 117.5 & 120.4 \\
$5-4-16$ & 119.5 & 117.4 & 116.8 \\
$5-15-17$ & 107.1 & 106.3 & 109.4 \\
$4-16-18$ & & 106.2 & 106.5 \\
$5-15-19$ & & & 110.9 \\
$5-15-20$ & & & 110.9
\end{tabular}

aromatic ring from the $\pi$ lone pair on oxygen is more effective than delocalization from the $\sigma$ lone pair. In addition, we found that the $\mathrm{O}-\mathrm{H}$ bond also adopts a cis conformation relative to the $\mathrm{C}-\mathrm{N}$ bond of the aromatic ring, thus favoring the formation of an $\mathrm{O}-\mathrm{H}-\mathrm{-}^{-\mathrm{N}}$ hydrogen bond, which further stabilizes this molecular conformation. As a consequence, an energetic barrier should occur for the torsional motion of the $\mathrm{O}-\mathrm{H}$ bond around the axis of the $\mathrm{C}-\mathrm{O}$ bond. To analyze the height of such a torsional barrier, we have also performed single-point B3LYP/ 6-311G** energy calculations for all the substituted quinoxalines with the respective $\mathrm{O}-\mathrm{H}$ bonds rotated by $90^{\circ}$ around the $\mathrm{C}-\mathrm{O}$ bonds and with all the remaining geometrical parameters frozen at their previously optimized values. The energies of both molecular conformations, shown in Table 6 , provide the following estimates of the $\mathrm{O}-\mathrm{H}$ torsional barriers: 43.1 $\mathrm{kJ} \cdot \mathrm{mol}^{-1}$ (2-hydroxyquinoxaline), $39.9 \mathrm{~kJ} \cdot \mathrm{mol}^{-1}$ (2,3-dihydroxyquinoxaline), and $44.7 \mathrm{~kJ} \cdot \mathrm{mol}^{-1}$ (2-hydroxy-3-methylquinoxaline). These results are substantially higher than the barriers calculated for phenol using the same computational methodology $\left(19.6 \mathrm{~kJ} \cdot \mathrm{mol}^{-1}\right)$ and for some substituted phenols ${ }^{17}(10-30$ $\mathrm{kJ} \cdot \mathrm{mol}^{-1}$ ) using DFT and the Becker-Perdew energy functional. ${ }^{18,19}$ This higher $\mathrm{O}-\mathrm{H}$ torsional barrier found for substituted quinoxalines can, at least in part, be considered as a consequence of the formation of the hydrogen bonds (the torsional barrier height for $\mathrm{OH}$-quinoxaline relative to its trans conformation is predicted to be only $15.9 \mathrm{~kJ} \cdot \mathrm{mol}^{-1}$ ).

The importance of the extended electronic delocalization from the $\pi$ lone pair of the oxygen atom to the aromatic ring is also evident from the predicted $\mathrm{C}-\mathrm{O}$ bond lengths $\left(R_{5,15}\right.$ and $R_{4,16}$ in Table 4), which are intermediate between that of a pure double bond $(1.225 \AA \text { in benzoquinone })^{20}$ and the mixed single-double bond in $\operatorname{phenol}^{21}(1.375 \AA)$.

Harmonic vibrational frequencies, allowing the calculation of energies at any temperature higher than $0 \mathrm{~K}$, were also obtained for these molecules through construction and diagonalization of the corresponding Hessian matrixes, using restricted Hartree-Fock (RHF) theory and the Pople 6-31G* double- $\zeta$ plus polarization (dzvp) basis set. ${ }^{22}$ The RHF method, which has the benefit of being much less computationally demanding than DFT/B3LYP, has, however, been reported to provide good estimates of the vibrational frequencies, which consistently overestimate the experimental ones by $\sim 10 \%$. Thus, the predicted harmonic vibrational frequencies were further scaled by 0.9 .

All RHF and B3LYP calculations were performed using the UK version of the program GAMESS. ${ }^{23,24}$

The relative stability of the substituted quinoxalines can be assessed through the energy (or enthalpy) of the reactions

$$
\begin{aligned}
& \mathrm{C}_{8} \mathrm{H}_{6} \mathrm{~N}_{2}+10 \mathrm{CH}_{4}+2 \mathrm{NH}_{3} \rightarrow \\
& 3 \mathrm{CH}_{2} \mathrm{CH}_{2}+4 \mathrm{CH}_{3} \mathrm{CH}_{3}+2 \mathrm{CH}_{2} \mathrm{NH}+2 \mathrm{CH}_{3} \mathrm{NH}_{2} \\
& \mathrm{C}_{8} \mathrm{H}_{6} \mathrm{~N}_{2} \mathrm{O}+11 \mathrm{CH}_{4}+2 \mathrm{NH}_{3} \rightarrow \\
& 3 \mathrm{CH}_{2} \mathrm{CH}_{2}+4 \mathrm{CH}_{3} \mathrm{CH}_{3}+2 \mathrm{CH}_{2} \mathrm{NH}+ \\
& 2 \mathrm{CH}_{3} \mathrm{NH}_{2}+\mathrm{CH}_{3} \mathrm{OH} \\
& \mathrm{C}_{8} \mathrm{H}_{6} \mathrm{~N}_{2} \mathrm{O}_{2}+12 \mathrm{CH}_{4}+2 \mathrm{NH}_{3} \rightarrow \\
& 3 \mathrm{CH}_{2} \mathrm{CH}_{2}+4 \mathrm{CH}_{3} \mathrm{CH}_{3}+ \\
& 2 \mathrm{CH}_{2} \mathrm{NH}+2 \mathrm{CH}_{3} \mathrm{NH}_{2}+2 \mathrm{CH}_{3} \mathrm{OH} \\
& \mathrm{C}_{9} \mathrm{H}_{8} \mathrm{~N}_{2} \mathrm{O}+12 \mathrm{CH}_{4}+2 \mathrm{NH}_{3} \rightarrow \\
& 3 \mathrm{CH}_{2} \mathrm{CH}_{2}+5 \mathrm{CH}_{3} \mathrm{CH}_{3}+2 \mathrm{CH}_{2} \mathrm{NH}+ \\
& 2 \mathrm{CH}_{3} \mathrm{NH}_{2}+\mathrm{CH}_{3} \mathrm{OH}
\end{aligned}
$$


TABLE 6. Calculated Energies (Hartree) ${ }^{a}$

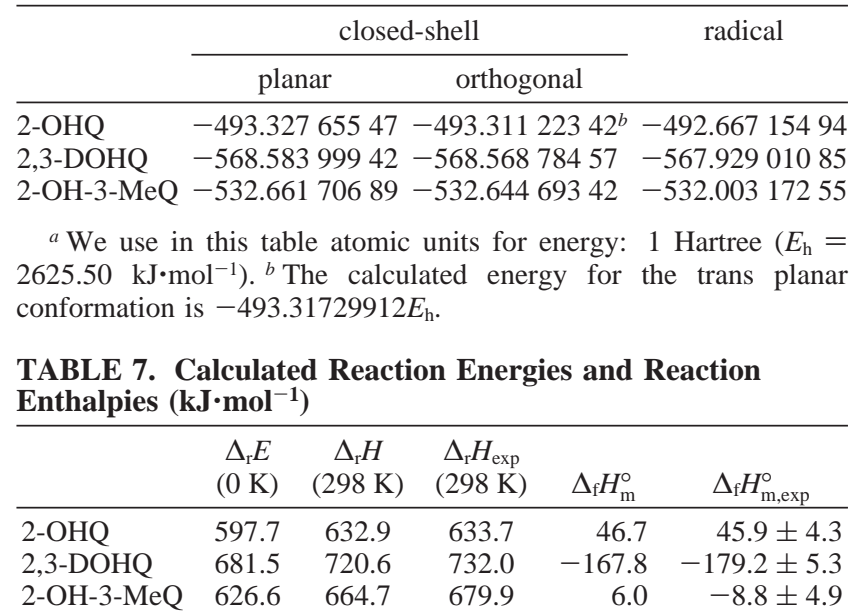

TABLE 8. Calculated O-H Dissociation Energies $\left(\mathrm{kJ} \cdot \mathrm{mol}^{-1}\right)$

\begin{tabular}{lc}
\hline & $D(\mathrm{O}-\mathrm{H})$ \\
\hline 2-hydroxyquinoxaline & 415.7 \\
2,3-dihydroxyquinoxaline & 401.3 \\
2-hydroxy-3-methylquinoxaline & 410.6
\end{tabular}

which, being of the isodesmic type, are likely to produce a substantial cancellation of the correlation errors introduced in the calculations. On the other hand, the use of such reactions provides estimates of the stabilizing effect of electronic delocalization and, since the auxiliary simple molecules are well studied experimentally, ${ }^{25}$ we will also be able to estimate the enthalpies of formation of the substituted quinoxalines. The energies of all auxiliary molecules have also been obtained using the same calculation procedures described for substituted quinoxalines. The resulting reaction energies at $0 \mathrm{~K}, \Delta_{\mathrm{r}} U(0 \mathrm{~K})$, reaction enthalpies at $298 \mathrm{~K}, \Delta_{\mathrm{r}} H(298 \mathrm{~K})$, and estimates of the heats of formation at $298 \mathrm{~K}, \Delta_{\mathrm{f}} H_{\mathrm{m}}^{\circ}$, are presented together with the corresponding experimentally observed values in columns 2-6 of Table 7 .

We can see from the results in Table 7 that the calculated energetics of the bond separation reactions are in very good agreement with the experimentally observed ones, with an average error of $9.4 \mathrm{~kJ} \cdot \mathrm{mol}^{-1}$, the worst case being 2-hydroxy3-methylquinoxaline, whose estimated heat of formation has an error of about $15.9 \mathrm{~kJ} \cdot \mathrm{mol}^{-1}$.

To estimate the $\mathrm{O}-\mathrm{H}$ bond strengths in the substituted quinoxalines, we have also optimized the geometries of the corresponding radicals using B3LYP/6-311G** calculations. The resulting electronic energies are shown in the last column of Table 6 , while the calculated $\mathrm{O}-\mathrm{H}$ bond dissociation energies, $D(\mathrm{O}-\mathrm{H})$, are shown in Table 8 . From the results we found that the substituted quinoxalines have generally larger $\mathrm{O}-\mathrm{H}$ dissociation energies than phenol, ${ }^{17}$ which at the same level of calculation has an $\mathrm{O}-\mathrm{H}$ bond dissociation energy of about $398 \mathrm{~kJ} \cdot \mathrm{mol}^{-1}$. The overall strengthening effect is mainly the result of the occurrence of $\mathrm{O}-\mathrm{H}-\mathrm{-}^{-\mathrm{N}}$ hydrogen bonds, which stabilize the closed-shell molecule. This effect is particularly evident for 2-hydroxyquinoxaline, since no additional effects are expected to come into play. For the disubstituted quinoxalines, interactions between the two ortho substituents may occur which can either oppose or reinforce the hydrogen bond stabilizing effect. The importance of the interaction between the substituents can be analyzed in terms of its effect on the closed-shell molecules, as the energy variation of the reactions

$$
\begin{gathered}
\mathrm{C}_{8} \mathrm{H}_{6} \mathrm{~N}_{2} \mathrm{O}_{2}^{\bullet}+\mathrm{C}_{8} \mathrm{H}_{6} \mathrm{~N}_{2} \rightarrow \mathrm{C}_{8} \mathrm{H}_{6} \mathrm{~N}_{2} \mathrm{O}+\mathrm{C}_{8} \mathrm{H}_{6} \mathrm{~N}_{2} \mathrm{O} \\
\mathrm{C}_{9} \mathrm{H}_{8} \mathrm{~N}_{2} \mathrm{O}+\mathrm{C}_{8} \mathrm{H}_{6} \mathrm{~N}_{2} \rightarrow \mathrm{C}_{8} \mathrm{H}_{6} \mathrm{~N}_{2} \mathrm{O}+\mathrm{C}_{9} \mathrm{H}_{8} \mathrm{~N}_{2}
\end{gathered}
$$

and the effect on the radicals considering the energy variation of the reactions

$$
\begin{gathered}
\mathrm{C}_{8} \mathrm{H}_{5} \mathrm{~N}_{2} \mathrm{O}_{2}^{\bullet}+\mathrm{C}_{8} \mathrm{H}_{6} \mathrm{~N}_{2} \rightarrow \mathrm{C}_{8} \mathrm{H}_{5} \mathrm{~N}_{2} \mathrm{O}^{\bullet}+\mathrm{C}_{8} \mathrm{H}_{6} \mathrm{~N}_{2} \mathrm{O} \\
\mathrm{C}_{9} \mathrm{H}_{7} \mathrm{~N}_{2} \mathrm{O}^{\bullet}+\mathrm{C}_{8} \mathrm{H}_{6} \mathrm{~N}_{2} \rightarrow \mathrm{C}_{8} \mathrm{H}_{5} \mathrm{~N}_{2} \mathrm{O}^{\bullet}+\mathrm{C}_{9} \mathrm{H}_{8} \mathrm{~N}_{2}
\end{gathered}
$$

where, in both cases, a positive reaction energy means a favorable (i.e. stabilizing) interaction between the substituents. In this way we were then able to observe that the interaction between the two substituents unstabilizes 2,3-dihydroxyquinoxaline by about $9 \mathrm{~kJ} \cdot \mathrm{mol}^{-1}$, a fact that can be attributed to a saturation effect on electronic delocalization, which occurs because both substituents are $\pi$-electron donor groups. This saturation effect is not present on 2-hydroxy-3-methylquinoxaline, for which the two substituents interact, producing a marginal stabilization of $<4 \mathrm{~kJ} \cdot \mathrm{mol}^{-1}$. For the corresponding radicals, the interaction between the oxygen atom and the other substituent has in both cases a stabilizing effect, amounting to about 5 and $8 \mathrm{~kJ} \cdot \mathrm{mol}^{-1}$, respectively, for 2,3-dihydroxyquinoxaline and 2-hydroxy-3-methylquinoxaline. This stabilizing effect occurs because the $\pi$-electron acceptor oxygen atom can enhance electronic delocalization. The combined result of these effects is then that both disubstituted quinoxalines have a smaller $\mathrm{O}-\mathrm{H}$ dissociation energy than 2-hydroxyquinoxaline. The $\mathrm{O}-\mathrm{H}$ dissociation energy of 2-hydroxy-3-methylquinoxaline is indeed very close to that estimated for phenol.

Acknowledgment. Thanks are due to Junta Nacional de Investigação Científica e Tecnológica (J.N.I.C.T.) for financial support of projects PBIC/C/CEN/1019/92 and PRAXIS XXI/ 2/2-1/QUI/54/94 as well as to Centro de Investigação em Química, University of Porto (Q.P./1-L.5). C.M.A.R. thanks J.N.I.C.T. for the award of a research grant under PRAXIS XXI (research grant BM/2003/94). M.S.M. thanks F.C.T. for the award of a research grant under PRAXIS XXI (research grant BD/9287/96).

\section{References and Notes}

(1) Ribeiro da Silva, M. A. V.; Matos, M. A. R.; Morais, V. M. F. J. Chem. Soc., Faraday Trans. 1995, 91, 1907.

(2) Ribeiro da Silva, M. A. V.; Morais, V. M. F.; Matos, M. A. R.; Rio, C. M. A.; Piedade, C. M. G. S. Struct. Chem. 1996, 7, 329.

(3) Padmaja, N.; Ramakumar, S.; Viswamitra, M. A. Acta Crystallogr., Sect. C 1987, 43, 2239.

(4) Ribeiro da Silva, M. A. V.; Ribeiro da Silva, M. D. M. C.; Pilcher, G. Rev. Port. Quim. 1984, 26, 163.

(5) Ribeiro da Silva, M. A. V.; Ribeiro da Silva, M. D. M. C.; Pilcher, G. J. Chem. Thermodyn. 1984, 16, 1149.

(6) Coops, J.; Jessup, R. S.; Van Nes, K. In Experimental Thermochemistry; Rossini, F. D., Ed.; Interscience: New York, 1956; Vol. 1, Chapter 3.

(7) The NBS Tables of Chemical Thermodynamic Properties. J. Phys. Chem. Ref. Data 1982.

(8) Hubbard, W. N.; Scott, D. W.; Waddington, G. In Experimental Thermochemistry; Rossini, F. D., Ed.; Interscience: New York, 1956; Vol. 1, Chapter 5.

(9) I.U.P.A.C. J. Phys. Chem. Ref. Data 1997, 26, 1239.

(10) Adedeji, F. A.; Brown, D. L. S.; Connor, J. A.; Leung, M.; PazAndrade, M. I.; Skinner, H. A. J. Organomet. Chem. 1975, 97, 221.

(11) Stull, D. R.; Westrum, E. F.; Sinke, G. C. The Chemical Thermodynamics of Organic Compounds; Wiley: New York, 1969.

(12) Rossini, F. D. In Experimental Thermochemistry; Rossini, F. D., Ed.; Interscience: New York, 1956; Vol. 1, Chapter 14.

(13) J. Chem. Thermodyn. 1978, 10, 903.

(14) Becke, A. D. J. Chem. Phys. 1993, 98, 5648. 
(15) Krishnan, R.; Frisch, M. J.; Pople, J. A. J. Chem. Phys. 1980, 74, 4244.

(16) Almeningen, A.; Bastiansen, O.; Fernholt, L.; Cyvin, B. N.; Cyvin, S. J.; Sandal, S. J. Mol. Struct. 1985, 128, 59.

(17) Ribeiro da Silva, M. A. V.; Matos, M. A. R.; Morais, V. M. F.; Miranda, M. S. J. Org. Chem. 1999, 64, 8816.

(18) Becke, A. D. Phys. Rev. A: At., Mol., Opt. Phys. 1988, A38, 3098.

(19) Perdew, J. P. Phys. Rev. B: Condens. Matter. 1986, B33, 8822.

(20) Hagen, K.; Headberg, K. J. Chem. Phys. 1973, 59, 158.

(21) Larsen, N. W. J. Mol. Struct. 1979, 51, 175

(22) Hariharan, P. C.; Pople, J. A. Chem. Phys. Lett. 1972, 66, 217.

(23) GAMESS U.K. is a package of ab initio programs written by Guest, M. F.; van Lenthe, J. H.; Kendrick, J.; Schoffel, K.; and Sherwood, P. with contributions from Amos, R. D.; Buenker, R. J.; van Dam, H. J. J.; Dupuis, M.; Handy, N. C.; Hillier, I. H.; Knowles, P. J.; Bonacic-Koutecky, V.; von Niessen, W.; Harrison, R. J.; Rendell, A. P.; Saunders, V. R.; Stone, A. J.; and de Vries, A. H. The package is derived from the original GAMESS code due to Dupuis, M.; Spangler, D.; Wendoloski, J. NRCC Software Catalog; 1980; Vol. 1, Program No. QG01 (GAMESS).

(24) The DFT module within GAMESS-UK was developed by Dr. P. Young under the auspices of EPSRC's Collaborative Computational Project No. 1 (CCP1), 1995-1997.

(25) Pedley, J. B. Thermochemical Data and Structures of Organic Compounds; TRC Data Series; Thermodynamics Research Center, College Station, Texas, 1994; Vol. 1. 